\title{
SELECTION FOR INCREASED GROWTH RATE IN INTER- AND INTRA-STRAIN CROSSES OF NEUROSPORA
}

\author{
K. E. PAPA,* A. M. SRB and W. T. FEDERER \\ Department of Plant Breeding, Cornell University, Ithaca, New Yark
}

Received 5.ii.66

\section{INTRODUCTION}

ANYONE studying quantitative inheritance almost automatically encounters complex problems which can usually be solved only partially or solved in the light of certain assumptions. An organism and experimental procedure chosen to minimise some of these complexities would be extremely desirable. The haploid inheritance in heterothallic Neurosporas, the short life cycle, the absence of heterosis and the ability to produce large numbers of offspring, both sexually and asexually, make certain species of this genus well suited for model studies of quantitative inheritance.

Problems of gene action, mutagenesis and recombination have been widely studied in microorganisms but little has been done with polygenic systems. Genetic variability must exist for a selection program to be effective, but storage of variability in heterozygotes is not possible in haploids. Bodmer and Parsons (1962) pointed out that the necessity for storing potential genetic variability is as important for microorganisms as for other organisms. The only mechanism capable of storing such variability, however, in the absence of heterozygosis or heterocaryosis, is the balanced polygenic complex.

Although very few selection experiments have been conducted on lower forms, an extensive literature has accumulated pertaining to selection in higher plants and animals. Chapman ( $196 \mathrm{I}$ ) has compiled an extensive bibliography pertaining to selection in laboratory animals. Kojima and Kelleher ( $196 \mathrm{I}$ ) have presented general information from Drosophila and mice experiments relevant to the planning of selection experiments and the understanding of genetic changes accompanying these experiments.

Polygenic inheritance in Neurospora was studied by Pateman (1955), (1959), Pateman and Lee (196o), Lee and Pateman (I959), (I96ı), and Lee (1962). In studying the effect of selection on ascospore size, they showed that phenotypic effects of polygenes on ascospore length were not simply additive but included a considerable amount of gene interaction. Linkage of part of the polygenic activity to the albino locus was also demonstrated.

Simchen and Jinks (1964), Simchen (1965) and Croft and Simchen

\footnotetext{
* Present address: Department of Plant Pathology and Plant Genetics, University of Georgia, Athens.
} 
(I965), working with Schizophyllum commune and Collybia velutipes, demonstrated the potential that fungi have in the elucidation of quantitatively inherited traits. Biometrical analyses of growth rate in dicaryons and their parental monocaryons provided an evaluation of genetic and environmental components of variation and also yielded knowledge of gene action in each stage.

Statistical theory of quantitative inheritance in haploids has been considered by Robson (1957), (1960). Genetic models were designed to fit two different breeding systems. Federer et al. (1966) formulated 4 selection models to describe populations undergoing selection. They applied one selection model to a set of data obtained from experiments of Papa (1964). Selection for an increased linear growth rate was practiced in Neurospora among progenies from inter- and intra-strain crosses. Estimates of the genetic and environmental components of variance were utilized in fitting the experimental data to the theoretical model. Generally quite good agreement was obtained between the observed and predicted response curves. Selection appeared to have reached asymptotic upper limits predicted by the model.

The work of Papa (Ig64) and Federer et al. (Ig66) was essentially a statistical approach to formulating and testing selection models. The intent of the present paper is to examine the selection results in more detail and in the light of existing genetical principles.

\section{MATERIALS AND METHODS}

(i) Strains

Neurospora strains from Honduras and from the Philippine Islands and the standard St Lawrence strains of $\mathcal{N}$. crassa, $74 \mathrm{~A}$ and $77 \mathrm{a}$, were utilised in this study. The strains of $74 \mathrm{~A}$ and $77 \mathrm{a}$ were supplied by D. Bonner while at Yale University. One mating type of the Honduras strain, Hon $3 \mathrm{~A}$, was obtained from R. N. Stover, Division of Tropical Research, United Fruit Company, LaLima, Honduras. The other mating type, Honıa, was obtained from S. R. Freiberg at San Alijo, Honduras. The two mating types of the Philippine Islands strain, 3-723-3A and 3-723-5a, were obtained as single ascospore isolates from a cross between $\mathrm{P}_{\mathrm{I}-3}$, furnished by $\mathrm{F}$. T. Orillo, College, Laguna, Philippine Islands, and an isolate collected by H. L. Everett, Cornell University, while at the Philippine Islands.

The necessity for maintenance of a high degree of fertility in crosses between widely differing strains was a major factor in the selection of the 3 strains to be used in this experiment. Previous crosses among these strains revealed that the $\mathcal{N}$. crassa and the Philippine Islands strains were quite similar, as judged by cross-compatibilities, whereas the Honduras strain was less compatible in crosses with the other two strains. $\mathcal{N}$. crassa, being the standard laboratory stock, undoubtedly has been fairly extensively inbred while the other strains have not. This is not to suggest, however, that opposite mating types of the laboratory stocks were isogenic.

\section{(ii) Media}

Media used in culturing and crossing were essentially those described by Beadle and Tatum (1954). Cultures were grown and maintained on a complete medium, whereas growth rates were measured on a minimal medium. A medium described by Westergaard and Mitchell (1947) was used for most crosses. Where difficulties were encountered in crossing on this medium, Difco Cornmeal agar was used. 


\section{(iii) Crosses}

Of the 18 possible crosses ( 9 crosses and their reciprocals) among the Neurospora strains used in this study, 14 were utilised. Initially only the standard $\mathcal{N}$. crassa and Honduras strains were included but it soon became apparent that more efficient use of time and facilities could be realised by handling additional material. Consequently crosses between the $\mathcal{N}$. crassa and Phillippine Islands strains were included.

The following 7 crosses plus their reciprical crosses were made. These crosses formed the basis for the experiments to be reported herein: $77 \mathrm{a} / 74 \mathrm{~A},{ }^{*}$ Hon3 $\mathrm{A} /$ Honla, 3-723-3A/3-723-5a, 77a/Hon $3 \mathrm{~A}, 74 \mathrm{~A} /$ Hon $1 \mathrm{a}, 77 \mathrm{a} / 3-723-3 \mathrm{~A}$ and $74 \mathrm{~A} / 3-723-5 \mathrm{a}$. In all subsequent crosses, cytoplasms were not controlled. All crosses were incubated at $25^{\circ} \mathrm{C}$.

\section{(iv) Growth tubes}

Growth rates were measured in specially constructed growth tubes as described by Ryan et al. (1943). All tubes were inoculated with 2-week-old conidia from cultures obtained from single spore isolates. The inoculated tubes were incubated at $18^{\circ}, 25^{\circ}$, or $35^{\circ} \mathrm{C}$. In each incubator the growth tubes were completely randomised and placed on the same shelf. After an appropriate lag period, at which time the mycelia became established and were advancing at a uniform rate down the tubes, the frontier of growth was marked on the top of the tube. Elimination of this lag period from consideration permitted discrepancies due to differing sizes of inoculum to be avoided. Due to the uniformity of growth rate over the entire distance of the tube following the lag period, only initial and final marks were made. The distance between the marks was measured and growth rates recorded in millimeters per hour.

Considerable effort was made to perfect a uniformity of technique in preparing media and in handling growth tubes from one experimental run to the next. Certain direct comparisons were made only within sets of growth tubes prepared and then run simultaneously.

\section{(v) Selection}

Selection for fast growth rate was conducted according to the procedure outlined in fig 1. Sixty ascospores were isolated at random from each cross. Forty of the

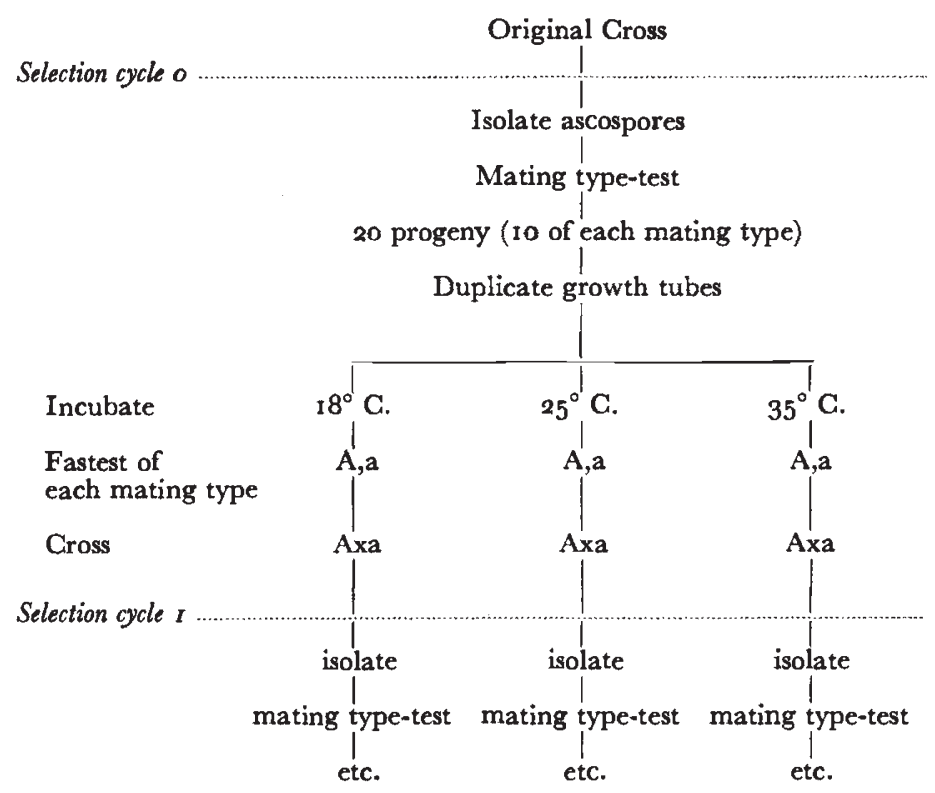

Fig. 1.-The selection procedure

\footnotetext{
* Conidial and protoperithecial parents on left and right of the diagonal, respectively.
} 
resulting vegetative cultures were randomly selected from each cross and mating type-tested. As germination percentage decreased in some of the lines, more than 60 ascospores were isolated and in some cases less than 40 cultures were mating typetested. From the vegetative cultures classified as to mating type, Io cultures of each mating type were randomly selected. Conidia from each of the 20 vegetative cultures (10 A's and Io a's) were transferred into duplicate growth tubes and incubated at $18^{\circ}, 25^{\circ}$, and $35^{\circ} \mathrm{C}$. Growth rates, based on the mean of duplicate tubes, were obtained for the 20 progeny at each of the 3 temperatures. The fastest growing two progeny of opposite mating type at each temperature were then crossed to give the next generation. Original vegetative cultures of the single ascospore isolates were retained throughout the mating type tests and growth rate determinations of these crosses. Thus, the individual isolates were maintained without subjecting them to unusual environmental stresses or selective pressures.

The crosses between the fastest individuals within each temperature gave rise to progenies which were isolated, mating type-tested and subjected to selection in the next cycle exactly in the same manner as already outlined. It should be stressed, however, that progeny isolated from crosses arising from the fastest parents at a particular temperature were subjected to selection only at that temperature in subsequent generations.

In order to obtain some idea of the sampling variability in the original 14 crosses a second sample of spores was taken from each original cross and the entire experiment repeated. Second samples were taken from all original crosses except $74 \mathrm{~A} /$ Hon Ia. By the time the second sample was taken from this cross, the few remaining ascospores would not germinate. Several attempts at remaking the cross failed.

In some lines infertility increased to a point that necessitated a relaxation of the selection pressure. In such cases, crosses were made between the second fastest and third fastest in addition to the fastest of each mating type. In most cases, ascospores were obtainable from one of these. In 3 instances, the slowest of each mating type were crossed in an effort to maintain certain lines. One line was discontinued after 3 cycles of selection and 3 more were discontinued after 4,5 , and 7 cycles.

\section{(vi) Direct vs. indirect responses to selection}

After to cycles of selection for fast growth rate, each line having arisen by selection at one temperature was observed at the other two temperatures. Sixty progeny from Ioth cycle crosses at all temperature levels were tested by taking single growth tube measurements on each in their previously selected temperature and also in the two unselected temperatures. To obtain the most accurate measure of direct and indirect responses, individuals selected continuously at each of the 3 temperatures for each cross and each replication were compared at the same time using the same batch of medium. Additional comparisons were made at several different cycles on the crosses involving $74 \mathrm{~A}$ as either parent. In these crosses it was found that the $F_{1}$ progenies were segregating with respect to temperature sensitivity. Information pertaining to the fate of the temperature sensitive gene(s), was obtained by comparing direct and indirect responses between the $F_{1}$ and $F_{10}$ generations.

\section{(vii) Reallsed heritability}

The usual method by which selection responses are portrayed is by plotting the mean of the selected character against the number of generations in which selection was practised. A method which is more informative from a genetic standpoint, as it takes into account the intensity of selection, is to plot the response against the cumulative selection differential. The linear regression of the response on the cumulative selection differential is defined as the realised heritability (Falconer, 1955). A regression coefficient corresponding to the realised heritability was obtained for each cross-temperature combination. In order to compare the various regression coefficients among crosses, temperatures and between reciprocal crosses, an analysis of 
variance was performed on the regression coefficients. Results from such an analysis are only approximate due to unequal variances of the regression coefficients. Such an analysis of variance, however, is analogous to an analysis of sub-class means consisting of disproportionate numbers. A more accurate analysis for the comparison of these coefficients was not considered necessary.

\section{(viii) Genetic variance}

An estimate of the genetic variance $\left(\sigma_{g_{\mathrm{oljk}}}^{2}\right)$ was obtained from each cycle (c), cross $(i)$, replication $(j)$, and temperature $(k)$ combination from the following analysis of variance.

\begin{tabular}{|c|c|c|c|}
\hline Source of variation & d.f. & m.s. & $E$ (m.s.) \\
\hline $\begin{array}{l}\text { Among progeny } \\
\text { Within progeny }\end{array}$ & $\begin{array}{l}\left(n_{\mathrm{cljk}} / 2\right)-1 \\
n_{\mathrm{cljk}} / 2\end{array}$ & $\begin{array}{l}A_{\mathrm{cijk}} \\
W_{\mathrm{cijk}}\end{array}$ & $\begin{array}{l}\sigma_{d}^{2}+2 \sigma_{g_{c 1, k}}^{2} \\
\sigma_{d}^{2}\end{array}$ \\
\hline
\end{tabular}

$\sigma_{g_{\mathrm{c} i \mathrm{jk}}}^{2}$ equals $\left(A_{\mathrm{cljk}}-W_{\mathrm{cijk}}\right) / 2$ and $\sigma_{d}^{2}$ is equal to the variance attributable to differences between duplicate measurements on the same individual. Normally $n_{\text {cijk }}$ was equal to $4^{\circ}$, thus representing 20 progeny, each duplicated. Occasionally some observations were missing in which case the above analysis was slightly modified.

Weighted averages of $\sigma_{g_{1 \mathrm{Jk}}}^{2}$ over cycles were utilised in fitting the selection results to a theoretical response curve (Federer et al., 1966).

\section{(ix) Error variance}

An estimate of the error variance $\left(\sigma_{e_{1 k}}^{2}\right)$ was obtained for each cross $(i)$ and temperature $(k)$ combination. The following analysis of variance on cycle means from both replications in each $i j$ combination was conducted.

\begin{tabular}{|l|l|l|}
\hline Source of variation & d.f. & $\mathrm{E}(\mathrm{m.s.})$ \\
\hline $\begin{array}{l}\text { Cycles } \\
\text { Within cycles }\end{array}$ & $\begin{array}{l}q-1 \\
q\end{array}$ & $\sigma_{e_{1 \mathbf{k}}}^{2}$ \\
\hline
\end{tabular}

$q$ is defined as the number of cycles in cross $i$ and temperature $k$ for which there are 2 replications. $\sigma_{e_{1 k}}^{2}$ is composed of error deviations from an assumed model, environmental variation, genetic variation, and/or error due to an incorrect model (Federer et al., 1966). The genetic portion of this component could arise from differences in the rate of fixation of genes and/or chance sampling of gene differences in the replicate selections.

\section{RESULTS}

(i) Selection

Selection for increased growth rate among progenies of inter- and intra-strain crosses at 3 different temperatures ( $18^{\circ}, 25^{\circ}$ and $35^{\circ} \mathrm{C}$.) was generally quite effective. A small portion of these selection responses along with the genetic variances at each cycle of selection are shown in figs. 2, 3, and 4. The selection responses were analysed and 
compared on the basis of realised heritability estimates. An example of the results obtained by selection in the cross Honra/Hon $3 \mathrm{~A}$ at $35^{\circ} \mathrm{C}$., when the response was measured against the cumulative selection differential, is portrayed in fig. 5. Only the realised heritabilities along with their standard errors are presented for the rest of the selection

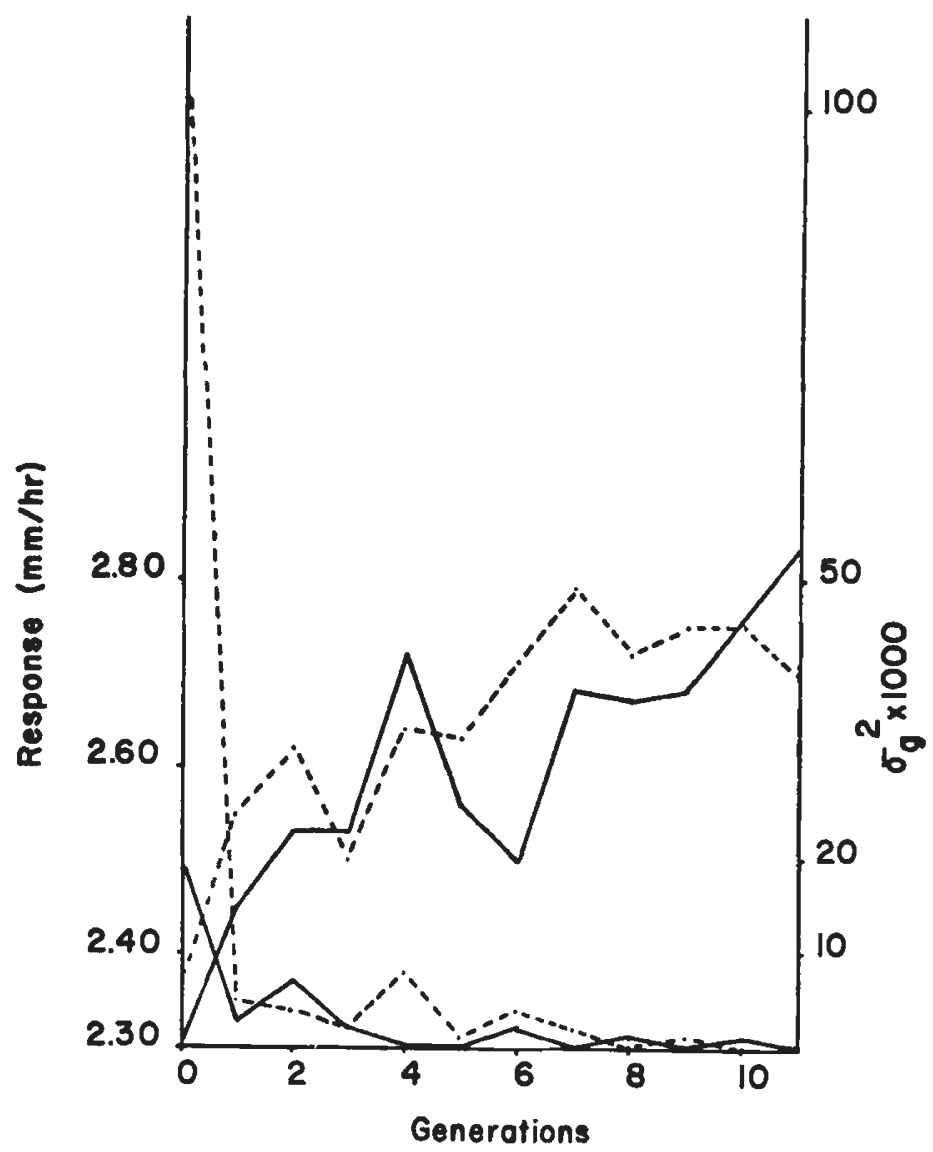

Fig. 2.-Response to selection for fast growth rate at $18^{\circ} \mathrm{C}$. in the cross Hon 1 a/Hon $3 \mathrm{~A}$. The solid and broken lines represent replications I and II, respectively. The lower 2 lines are the genetic variances for each cycle of each replication.

responses (table I). Each value was based on ten or eleven generations with the exception of cross $77 \mathrm{a} / \mathrm{Hon}_{3} \mathrm{~A}$ at $35^{\circ} \mathrm{C}$., which was based on only five generations. Selection differentials and mean responses at each generation were determined from the combination of both replications for all crosses except $74 \mathrm{~A} /$ Hon ra, which consisted of only one replication.

The selection responses presented in figs. 2, 3, and 4 are quite typical of the pattern of response noted from most crosses. There was generally quite good correspondence between replications with the exception of an occasional generation. These differences could usually 
be attributed to environmental influences and/or unfavorable genetic recombinants. An example of the former can be noted in generation 6 of replication I from cross Hon Ia/Hon $3 \mathrm{~A}$ at $25^{\circ}$ C. (fig. 3 ). The progeny were slow growing and quite uniform as evidenced by the small genetic variance. Reduced mean growth rate resulting from

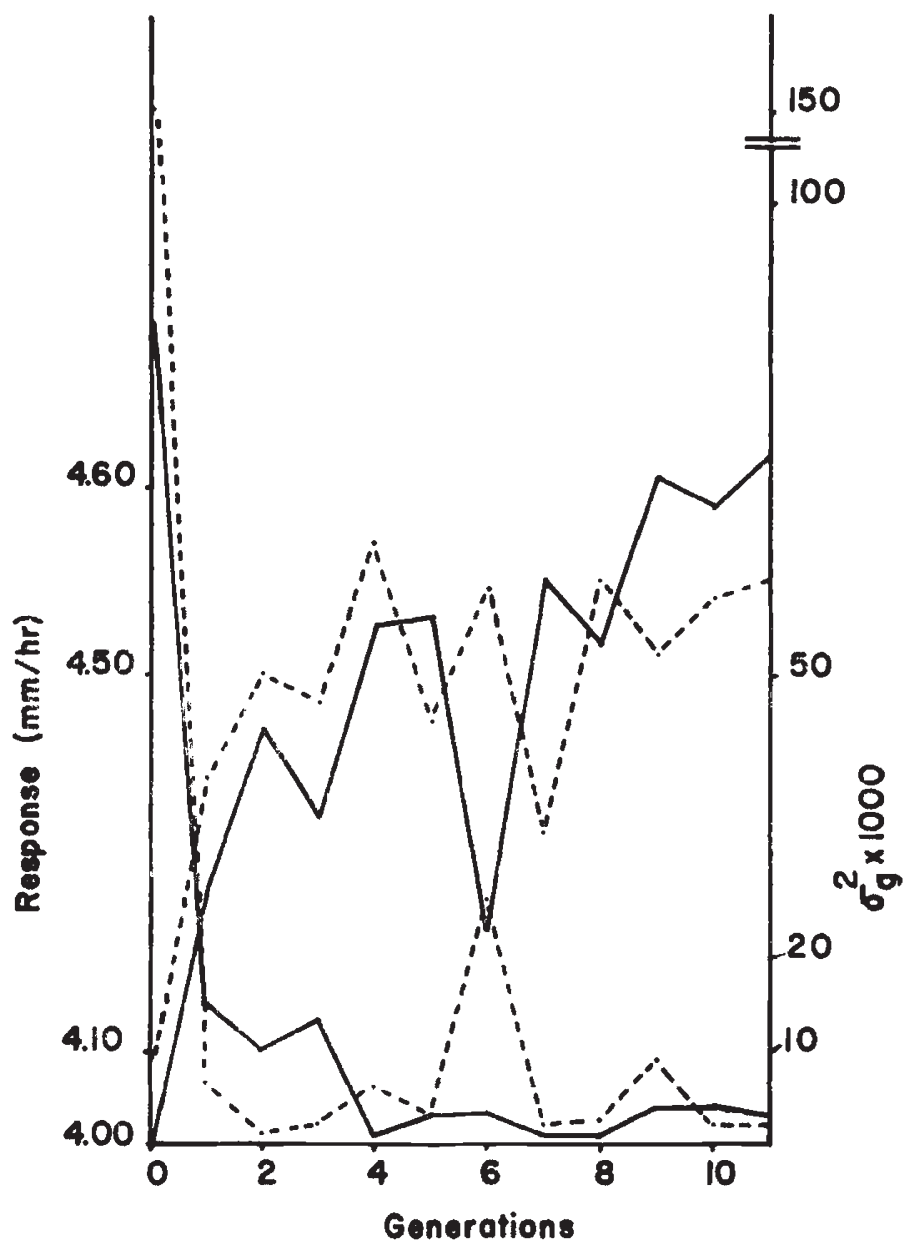

Fig. 3.-Response to selection for fast growth rate at $25^{\circ} \mathrm{C}$. in the cross Honia/Hon3A. For explanation see fig. 2.

the formation of unfavorable genetic recombinants was usually accompanied by an increased genetic variance. An example of this situation occurred in generation 8, replication 2, cross Hon Ia/Hon3A at $35^{\circ} \mathrm{C}$. (fig. 4). This is not to imply, however, that a high genetic variance necessarily results from the formation of unfavorable genetic recombinants.

The reduction of genetic variances shown in figs. 2, 3 and 4, was generally indicative of the trend observed in most crosses. From the 
degree of inbreeding, one would theoretically expect the genetic variance to be reduced by approximately $\frac{1}{2}$ in each generation. Exceptions to this step-wise reduction in the genetic variance occasionally occurred, however. An extremely high genetic variance arising in any one cycle could presumably be attributed to the effects of

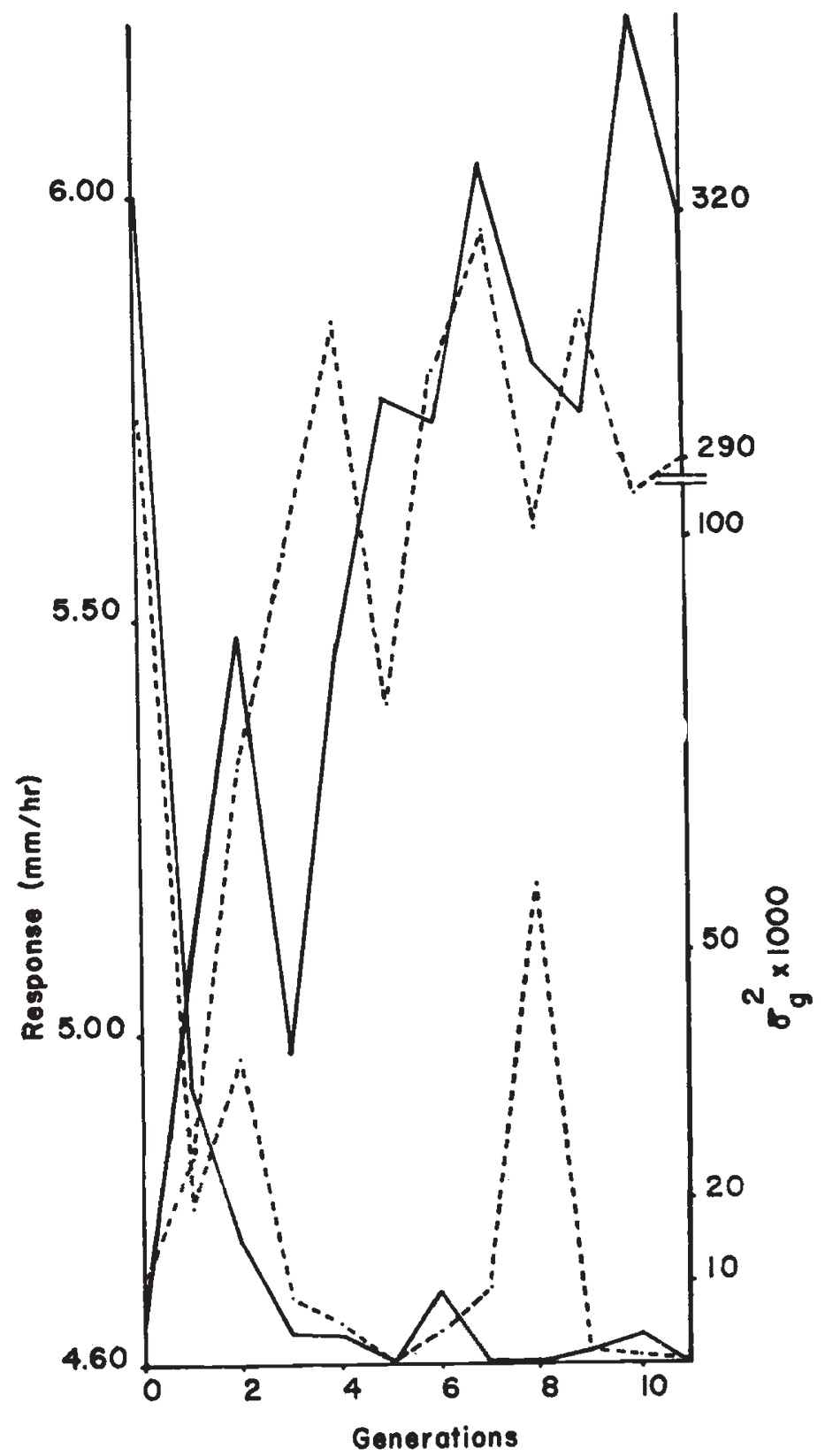

Fig. 4. - Response to selection for fast growth rate at $35^{\circ} \mathrm{C}$. in the cross Honia/Hon $3 \mathrm{~A}$. For explanation see fig. 2 . 
recombination and/or mutation. An example of this was noted in generation 8, replication 2 of cross Honra/Hon3A at $35^{\circ}$ C. (fig. 4), in which the progeny ranged in growth rate from 5 to $6 \mathrm{~mm}$. $/ \mathrm{hr}$. and were segregating into 3 classes. Similar effects were noted in occasional cycles of other crosses in which increased genetic variances were encountered.

$\sigma_{d}^{2}$ was generally quite small and uniform over cycles and crosses. It increased slightly with temperature but was quite uniform within a

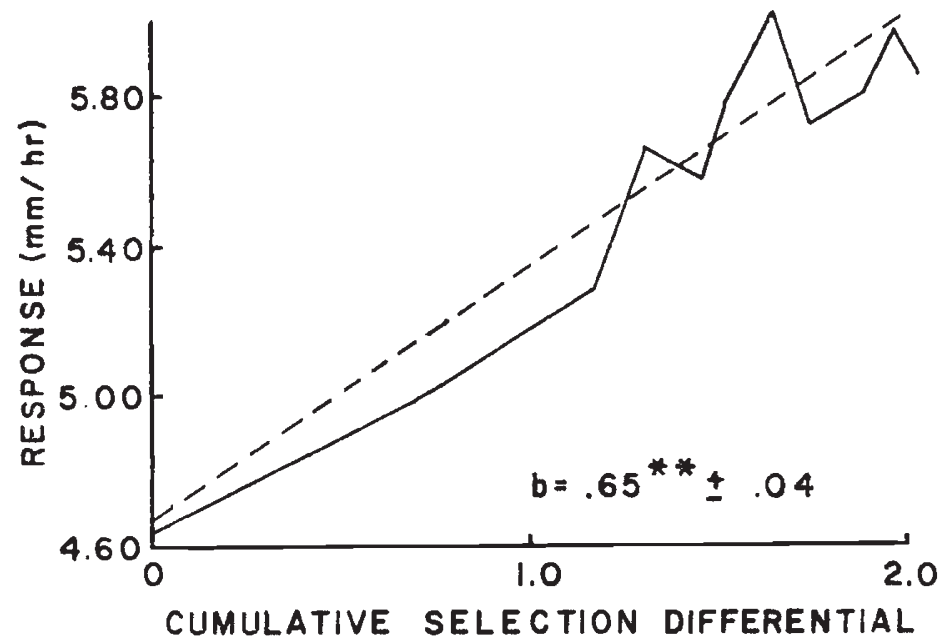

FiG. 5.-Response to selection for fast growth rate at $35^{\circ} \mathrm{C}$. in the cross Hon Ia/Hon3A. Mean response per generation plotted against the cumulative selection differential (solid line). Broken line is linear regression and $b$ the regression coefficient with standard error.

particular temperature. For example, $\sigma_{d}^{2}$ averaged over cycles and replications of the reciprocal crosses Hon 1 a/Hon $3 \mathrm{~A}$ and Hon $3 \mathrm{~A} / \mathrm{Hon}$ ia was equal to $0.00182,0.00433$ and 0.00506 at $18^{\circ}, 25^{\circ}$, and $35^{\circ} \mathrm{C}$., respectively. It was concluded that the temperature within a particular incubator was quite constant during the time necessary to obtain growth measurements from one set of growth tubes. Thompson (1960) arrived at a similar conclusion after testing the amount of variability among different sections within a $25^{\circ} \mathrm{C}$. incubator over a 6o-hour period.

Estimates of the error variances $\left(\sigma_{e}^{2}\right)$ for Hon Ia/Hon3A and Hon3A/Hon $r$ a at $18^{\circ}, 25^{\circ}$ and $35^{\circ} \mathrm{C}$., are given below.

\begin{tabular}{|c|c|c|c|}
\hline Cross & $18^{\circ}$ & $25^{\circ}$ & $35^{\circ}$ \\
\hline $\begin{array}{c}\text { Hon 1a/Hon3A } \\
\text { Hon3A/Hon1a }\end{array}$ & $\begin{array}{l}0.00487 \\
0.00629\end{array}$ & $\begin{array}{l}0.01343 \\
0.00651\end{array}$ & $\begin{array}{l}0.0514^{2} \\
0.0095^{2}\end{array}$ \\
\hline
\end{tabular}

As can be seen from the above table, the estimated error variances increase with temperature. The estimates for the other crosses followed 
the same pattern. Averaging the estimates over all 14 crosses at each temperature resulted in the following average error variances for $18^{\circ}, 25^{\circ}$ and $35^{\circ} \mathrm{C}$., respectively: $0 \cdot 00846$, 0.01895 and 0.10016 .

Most of the responses when measured as the realised heritability (table I) were significantly different from zero, indicating that selection for fast growth rate had been effective in most crosses. Considerable variation, however, was present among these responses. Also, variation among the temperature means is evident, the response at $18^{\circ} \mathrm{C}$. being midway between responses obtained at $25^{\circ}$ and $35^{\circ} \mathrm{C}$.

The variation among the cross means, combined reciprocal cross means and temperature means was tested by the analysis of variance shown in table 2.

Highly significant differences were obtained among temperatures when tested against the error variance. Using Tukey's hsd procedure, the mean responses at each temperature were significantly different from the rest at the $0 \cdot 0$ I level of significance.

The differences between these particular responses presumably reflect a difference in the availability of genetic variation at each of the 3 temperatures. The smaller realised heritability estimates at $25^{\circ} \mathrm{C}$., and therefore a slower rate of progress, could be attributed to the inefficiency of artificial selection at that temperature. Since $25^{\circ}$ more closely resembles the temperature at which most of the strains were cultured prior to selection, natural selection in favor of an internal balance within certain polygenic complexes had perhaps been operating. Progress from artificial selection practised at $25^{\circ}$ would therefore be impeded by the effects of previous natural selection. Artificial selection at $18^{\circ}$ and $35^{\circ}$, however, appears to have been effective in modifying the effects of natural selection, thereby increasing the availability of genetic variation. The availability of genetic variation was presumably greater at $35^{\circ}$ than at $18^{\circ} \mathrm{C}$. This might be expected since $18^{\circ}$ more closely resembles the temperature to which the strains had become adapted prior to selection than does $35^{\circ} \mathrm{C}$.

As a consequence of the differential availability of genetic variation with temperature, selection limits should be reached sooner at $18^{\circ}$ and $35^{\circ}$ than at $25^{\circ} \mathrm{C}$. The number of generations involved in these experiments may not have been adequate to determine whether limits had been reached in lines selected at $18^{\circ}$ and $35^{\circ}$ and not at $25^{\circ}$. The results from direct and indirect selection responses, however, which indicate that more variability was retained in lines selected continuously at $25^{\circ}$ than at either $18^{\circ}$ or $35^{\circ}$, tend to support the argument developed above.

From the analysis of variance in table 2, the mean square for among crosses (reciprocals combined) was significantly greater than the mean square for temperature by reciprocals combined. By using the hsd to compare individual cross means, a significantly less response was obtained by selecting in crosses between $74 \mathrm{~A}$ and $77 \mathrm{a}$ than in any other cross. This was not surprising since at the beginning of these selection 


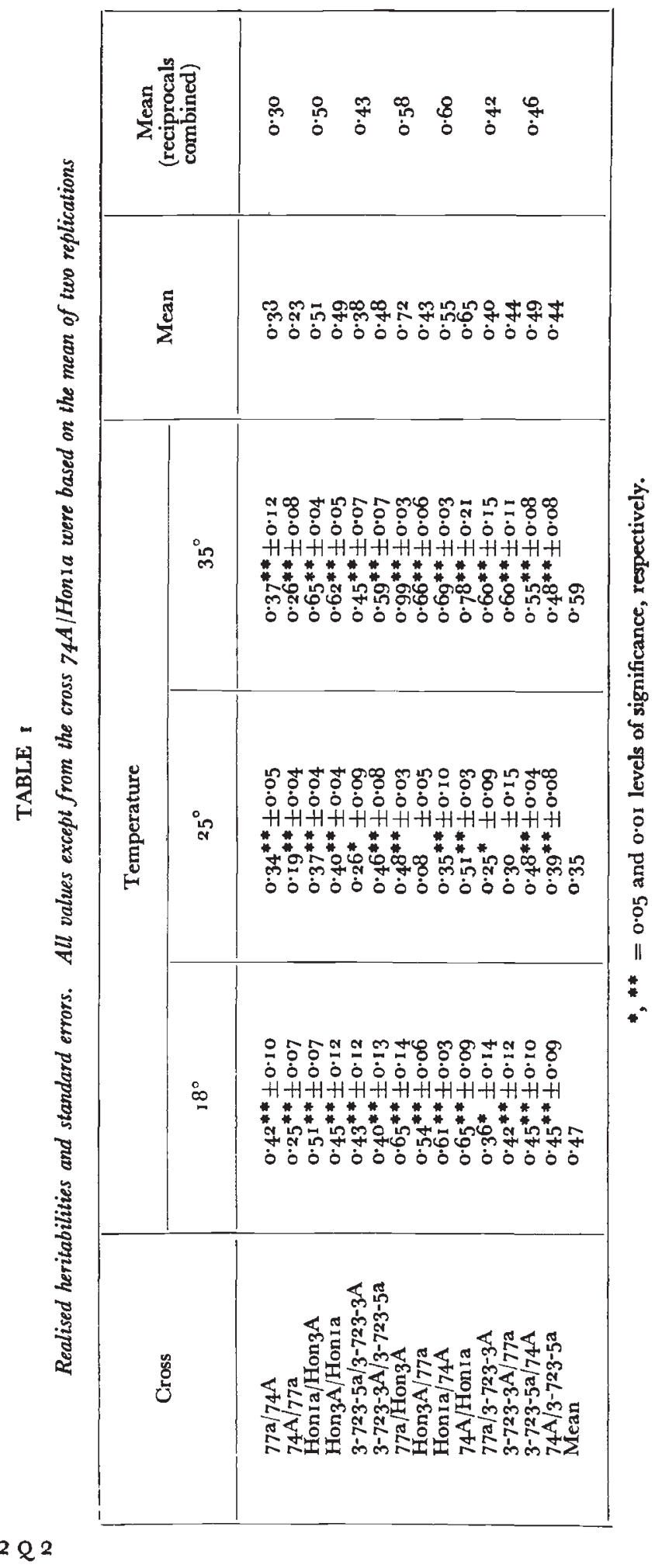


experiments $74 \mathrm{~A}$ and $77 \mathrm{a}$ were undoubtedly more highly inbred than were the other strains. Therefore, although significant responses were obtained in the two reciprocal crosses involving these two strains, the reduction in the variability considerably reduced the potential for a greater response.

No significant differences were obtained among crosses of the following: Hon $3 \mathrm{~A}$ and Hon Ia, 3-723-3A and 3-723-5a, 3-723-3A and $74 \mathrm{~A}$, and $3-723-5 \mathrm{a}$ and $74 \mathrm{~A}$; nor among Hon $3 \mathrm{~A}$ and Hon ra, Hon $3 \mathrm{~A}$

TABLE 2

Analysis of variation among realised heritability estimates

\begin{tabular}{|l|r|c|}
\hline \multicolumn{1}{|c|}{ Source of variation } & $\mathrm{df}$ & Mean squares \\
\hline Temperatures & 2 & $0.210 \mathrm{I}^{* *}$ \\
Crosses & 13 & $0.058^{*}$ \\
Combinations (reciprocals combined) & 6 & $0.0265^{* *}$ \\
Reciprocals within combinations & 7 & $0.0155^{* *}$ \\
Temperatures $\times$ Crosses & 26 & 12 \\
Temperatures $\times$ Combinations & 14 & 0.0034 \\
Temperatures $\times$ Reciprocals w/n Combinations & & \\
\hline
\end{tabular}

*, **_-significance at the 0.05 and 0.01 levels of probability, respectively.

and $77 \mathrm{a}$, and Hon ra and $74 \mathrm{~A}$. The responses obtained from crosses between Hon $3 \mathrm{~A}$ and $77 \mathrm{a}$, as well as between Honia and $74 \mathrm{~A}$, were significantly greater than those obtained for any other combination except between Hon3A and Honra. Crosses between the Philippine Islands strains $(3-723-3 \mathrm{~A},-5 \mathrm{a})$ and either $74 \mathrm{~A}$ or $77 \mathrm{a}$ showed no superiority over intra-strain crosses of the Philippine Islands strains.

Significant differences were obtained between reciprocal crosses, as shown in table 2. With the $h s d$, a significant difference was obtained only between $77 \mathrm{a} / \mathrm{Hon}_{3} \mathrm{~A}$ and its reciprocal cross. An F-test on comparisons with one degree of freedom for each reciprocal pair, however, also resulted in a highly significant difference between $77 \mathrm{a} / 74 \mathrm{~A}$ and its reciprocal cross.

An extremely high heritability at $35^{\circ}$ in $77 \mathrm{a} / \mathrm{Hon}_{3} \mathrm{~A}$ and an extremely low heritability at $35^{\circ}$ in Hon $3 \mathrm{~A} / 77 \mathrm{a}$ accounted for most of the difference between this reciprocal pair. The extremely high heritability in the one case was probably partially due to the fewer generations (5) of selection being involved in the estimate. In addition, in one generation the progeny mean of one replication far exceeded either parent, thereby contributing considerably to an increased heritability. Selection was discontinued in both replications of this line at $35^{\circ}$ due to extreme infertility problems.

The extremely low heritability $(0 \cdot 08)$ obtained at $25^{\circ} \mathrm{C}$. for Hon3A/77a was indicative of an almost complete lack of response to selection. Essentially no increase in growth rate was observed in one replication, whereas in the other replication an approximately linear 
increase was obtained for the first five generations followed by a sharp decline. Recovery of the level of growth rate achieved prior to the decline was not obtained by the eleventh generation. Presumably, unfavorable genetic recombinants were obtained which had to be eliminated before additional progress could be made. No detectable adverse effects on fertility, however, were found to be accompanying this decline in growth rate.

In Table $\mathrm{I}$, the response from selection in $77 \mathrm{a} / 74 \mathrm{~A}$ was consistently greater than in its reciprocal cross at all 3 temperatures. By figuring the realised heritability separately for each replication of these 2 reciprocal crosses, essentially the same results were obtained. Whether the difference in response between these 2 lines can be attributed to cytoplasmic effects is not certain. The $\mathrm{F}_{1}$ progeny means for both replications at all 3 temperatures of $77 \mathrm{a} / 74 \mathrm{~A}$ were less than the corresponding measurements of the $F_{1}$ progeny means of $74 \mathrm{~A} / 77 \mathrm{a}$, yet approximately the same upper limits were achieved for both crosses at the same temperature. Therefore, the fact that selection in $77 \mathrm{a} / 74 \mathrm{~A}$ began at a lower level, yet reached essentially the same upper limit as selection in $74 \mathrm{~A} / 77 \mathrm{a}$, would account for the difference in the realised heritabilities.

With the exception of reciprocal differences between crosses of $74 \mathrm{~A}$ and $77 \mathrm{a}$, there is little, if any, evidence to suggest the presence of cytoplasmic effects on growth rate. Perhaps extra-chromosomal effects are present but are too minor to detect by the comparison of realised heritabilities.

\section{(ii) Direct vs. indirect responses to selection}

Measures of the indirect responses to selection were obtained by comparing the progeny means of lines subjected to selection at 3 different temperatures when grown at the same temperature. Data were obtained from 20 such comparisons involving i I of the I4 crosses, each replicated twice except two. Quite similar growth rates were obtained in many of the lines regardless of the temperature at which prior selection had been practised. By comparing the mean responses of direct and indirect selection over all crosses and replications, the direct selection slightly exceeded either of the two indirect methods. A summary of these results, involving overall mean responses, is presented in table 3 .

Individual comparisons among means and variances, although not presented, indicated that direct selection at $18^{\circ}$ generally resulted in significantly higher growth rates than did indirect selection at $25^{\circ}$ and $35^{\circ} \mathrm{C}$. Although significant differences occurred between the two indirect methods at $18^{\circ}$, neither method was consistently better than the other. Comparisons among direct and indirect responses for growth rate at $25^{\circ}$ indicated that direct selection at $25^{\circ}$ was significantly better than indirect selection at either $18^{\circ}$ or $35^{\circ}$ in most of the lines tested. Indirect selection for fast growth rate at $25^{\circ} \mathrm{C}$. was generally better 
when practised at $18^{\circ}$ than at $35^{\circ}$. For fast growth rate at $35^{\circ}$, direct selection was almost consistently better than either indirect method. Indirect selection at $35^{\circ}$ resulted in the exposure of some lines which were not adapted for growth at that temperature.

Direct selection at $18^{\circ}$ and $35^{\circ}$ resulted in lower variances among the progeny than either of the indirect methods. Of the indirect methods for obtaining improved growth rate at $18^{\circ}$ and $35^{\circ}$, indirect selection at $25^{\circ}$ was generally associated with a higher among progeny variance. Temperature sensitive progeny contributed much of the variability of indirect selection methods for improved growth rate at $35^{\circ}$. However, by disregarding these progeny, indirect selection for fast growth rate at $35^{\circ}$ was still associated with a higher variance than was direct selection.

TABLE 3

Progeny means and variances of lines previously selected for fast growth rate at $18^{\circ}, 25^{\circ}$ or $35^{\circ} \mathrm{C}$. when grown at the same temperature. Each of the growth rates and variances represents the average of 20 sets of progeny means, each mean having been calculated on the basis of 60 progeny.

\begin{tabular}{|c|c|c|c|}
\hline Temperature & $\begin{array}{c}\text { Selection } \\
\text { Temperature }\end{array}$ & $\begin{array}{l}\text { Growth rate } \\
(\mathrm{mm} . / \mathrm{hr} .)\end{array}$ & Variance \\
\hline $\begin{array}{l}18^{\circ} \\
25^{\circ} \\
35^{\circ}\end{array}$ & $\begin{array}{l}18^{\circ} \\
25^{\circ} \\
35^{\circ} \\
18^{\circ} \\
25^{\circ} \\
35^{\circ} \\
18^{\circ} \\
25^{\circ} \\
35^{\circ}\end{array}$ & $\begin{array}{l}2 \cdot 64 \\
2 \cdot 58 \\
2 \cdot 56 \\
4.24 \\
4.28 \\
4 \cdot 19 \\
4.85 \\
4.22 \\
5.3^{8}\end{array}$ & $\begin{array}{l}\text { o.0029I } \\
\text { o.00632 } \\
\text { o.00302 } \\
\text { o.0o66o } \\
\text { o.0o6 } \\
\text { o.0o639 } \\
\text { o.03839 } \\
\text { o.0753 I } \\
\text { o.01369 }\end{array}$ \\
\hline
\end{tabular}

From these observations it can be concluded that considerably more variability was retained during selection at $25^{\circ}$ than at either $18^{\circ}$ or $35^{\circ} \mathrm{C}$. The reason is undoubtedly associated with the fact that prior to selection the strains included in this study were better adapted to an intermediate temperature at or near $25^{\circ} \mathrm{C}$. Consequently, much of the variability present in the initial strains could be retained during continuous selection at $25^{\circ}$. Apparently, much of this variability could be attributed to the segregation of genes which were relatively unimportant in controlling growth rate. Many of these genes, however, when subjected to extreme temperatures, were at a definite disadvantage and were selected against. Therefore, only the genotypes particularly favorable at extreme temperatures could be retained during selection for fast growth rate at $18^{\circ}$ and $35^{\circ} \mathrm{C}$.

(iii) Temperature sensitivity

An interesting phenomenon occurred during indirect selection for fast growth rate at $35^{\circ} \mathrm{C}$. In some crosses, involving $74 \mathrm{~A}$, and which 
had been subjected to selection at $18^{\circ}$ and $25^{\circ}$, all of the progeny had an extremely slow growth rate at $35^{\circ} \mathrm{C}$. A slow, rather uniform growth rate persisted for approximately 24 to 36 hours and gradually decreased until growth had essentially ceased. This particular phenomenon was presumably due to the presence of temperature sensitive, mutant alleles in $74 \mathrm{~A}$. The $F_{1}$ progeny from crosses, involving $74 \mathrm{~A}$ as either parent and when grown at $35^{\circ} \mathrm{C}$., were all segregating in the ratio of one normal to one temperature sensitive. A considerable amount of variability, however, existed among the temperature sensitive $F_{1}$ progeny.

To obtain information concerning the fixation or elimination of the temperature sensitive allele(s) during selection at three temperatures,

TABLE 4

Retention and elimination of temperature sensitive allele(s) during selection for fast growth rate at $18^{\circ}$ and $25^{\circ} \mathrm{C}$.

\begin{tabular}{|c|c|c|c|c|c|}
\hline \multirow{2}{*}{ Cross } & \multirow{2}{*}{$\begin{array}{l}\text { Repli- } \\
\text { cation }\end{array}$} & \multicolumn{2}{|c|}{$F_{2}$ Parents } & \multicolumn{2}{|c|}{ 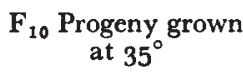 } \\
\hline & & $18^{\circ}$ & $25^{\circ}$ & $18^{\circ}$ & $25^{\circ}$ \\
\hline & 1 & $\mathrm{TS} \times \mathrm{N}^{*}$ & $\mathbf{T S} \times \mathbf{N}$ & $\mathrm{N}$ & TS \\
\hline $77 \mathrm{a} / 74^{\mathrm{A}}$ & 2 & $\mathrm{TS} \times \mathrm{N}$ & $\mathrm{TS} \times \mathbf{T S}$ & $\mathrm{N}$ & $\mathrm{TS}$ \\
\hline $74 \mathrm{~A} / 77 \mathrm{a}$ & I & $\begin{array}{l}\mathrm{TS} \times \mathrm{TS} \\
\mathbf{N} \times \mathbf{N}\end{array}$ & $\underset{T S}{N} \times \mathbf{T S}$ & TS & TS \\
\hline & $\begin{array}{l}2 \\
I\end{array}$ & $N \times T S$ & $\mathbf{N} \times \mathbf{N}$ & $\mathrm{N}$ & N \\
\hline $74 \mathrm{~A} / 3-723-5 \mathrm{a}$ & 2 & $\mathrm{~N} \times \mathrm{TS}$ & $\mathrm{N} \times \mathrm{TS}$ & $\mathrm{N}$ & TS \\
\hline $3-723-5 \mathrm{a} / 74 \mathrm{~A}$ & I & $\mathbf{T S} \times \mathbf{N}$ & $\mathrm{TS} \times \mathbf{N}$ & $\mathbf{N}$ & TS \\
\hline 3. & 2 & $\mathbf{N} \times \mathbf{T S}$ & $\mathrm{TS} \times \mathbf{T S}$ & TS & TS \\
\hline 74A/Hon Ia & $\mathbf{I}$ & & $\mathbf{N} \times \mathbf{N}$ & $\mathbf{N}$ & TS \\
\hline
\end{tabular}

* TS equals temperature sensitive, $\mathrm{N}$ equals normal

their presence or absence was determined at varying stages of selection. Since the $F_{1}$ progeny of each cross were grown at three temperatures, it was possible to detect whether parents selected from the $F_{1}$ at $18^{\circ}$ and $25^{\circ}$ C. were temperature sensitive. Selection for fast growth rate at $35^{\circ}$ C. resulted in the elimination of this character after one cycle of selection in most crosses and after two cycles in the rest. The phenotypic expression of temperature sensitivity, however, was not detectable in the lines continuously selected at $18^{\circ}$ and $25^{\circ} \mathrm{C}$.

Individuals chosen as parents from the $F_{1}$ progeny of each cross involving $74 \mathrm{~A}$ grown at $18^{\circ}$ and $25^{\circ} \mathrm{C}$., are shown in table 4 . The parents are designated only as TS (temperature sensitive) or N (normal). After nine additional cycles of selection for fast growth rate, the $\mathrm{F}_{10}$ progeny were scored as being either TS or N.

In all instances in which either or both $F_{2}$ parents were TS at $25^{\circ} \mathrm{C}$., TS was retained during selection for fast growth rate. Since it was not present in the $F_{2}$ parents, TS was undoubtedly acquired by mutation or contamination during selection in $74 \mathrm{~A} / \mathrm{Hon} r$ a at $25^{\circ} \mathrm{C}$. 
Lines which originally carried TS alleles at $18^{\circ}$, were tested to determine at what stage in selection these alleles were lost. The $\mathbf{F}_{2}$ progeny of 3 crosses were segregating in the ratio of one TS to one N. The $F_{3}$ progeny of the same 3 crosses, however, were all normal. In two other crosses, second cycle progeny had been discarded and could not be tested; however, the third cycles were normal. In crosses $74 \mathrm{~A} / 77 \mathrm{a}$, replication one, and 3-723-5a/74, replication two, TS was retained throughout all stages of selection at $18^{\circ} \mathrm{C}$. In $74 \mathrm{~A} / 77 \mathrm{a}$ both of the $F_{2}$ parents presumably carried the same TS allele(s) and thus TS was genotypically fixed as early as the $F_{2}$. The other cross, 3-723-5a/74A, was segregating in the fifth cycle and was completely TS in the sixth and subsequent cycles. The $\mathrm{F}_{2}-\mathrm{F}_{4}$ progenies from this cross should have been grown at $35^{\circ}$ in order to ascertain whether selection at $18^{\circ}$ in the early generations of this line also caused the elimination of TS. If TS was eliminated, then the TS progeny observed segregating in the $F_{5}$ would have resulted from a new mutation.

\section{DISCUSSION}

The fact that considerable variability was present in the original unselected parental cultures was evidenced by the effectiveness of selection for fast growth rate in the progeny of crosses between these lines. For a selection program to be effective, variability must be present or be induced. Using the amount of response as the measure of original variability, considerably more variation existed in the Honduras strains than in either the Philippine Islands strains or $74 \mathrm{~A}$ and 77a. Selection in crosses between the Honduras strains and either $74 \mathrm{~A}$ or $77 \mathrm{a}$, however, resulted in the greatest responses. Presumably these two lines were genetically quite different, thereby allowing for the recovery of genetic recombinants with favourable genes for growth.

Infertility problems which were encountered in crosses between the Honduras strains and either $74 \mathrm{~A}$ or 77 a were further suggestive of considerable genetic differences between these two strains. Although crosses between the Philippine Islands and Honduras strains were not included in this study, one might predict the selection responses from such crosses would be similar to those observed between Honduras strains and either $74 \mathrm{~A}$ or $77 \mathrm{a}$. This prediction is based primarily on the similarities and the high degree of compatibility between the Philippine Islands strains and either $74 \mathrm{~A}$ or $77 \mathrm{a}$.

Infertility problems were primarily manifest in fewer perithecia being formed, ascospores failing to mature and an increased frequency of mature ascospores failing to germinate. Similar phenomena were observed by Lee and Pateman (196r) in the selection for large ascospores in Neurospora crassa. Reduction in fertility occurred at all three temperatures and at varying stages in the selection program. In some lines, infertility problems were encountered after two or three cycles of selection but were overcome by the fifth or sixth cycle. In others, in which these problems were never overcome, the selection pressure had 
to be relaxed and in certain cases selection had to be discontinued. In still others, loss of fertility was not encountered until after six or seven cycles of selection. Some of the inter-strain crosses, however, exhibited no infertility problems.

Reduced fitness accompanying inbreeding and artificial selection has been extensively examined by Lerner (1954), as well as by Mather and Harrison (1949), Thoday (1958) and many others. While most of the ideas put forth by these and other investigators have evolved from experimental work with diploids, many of them are applicable to haploid systems. Both systems are capable of building up homeostatic complexes of genes which can confer a certain degree of stability on the organism as well as provide for a reservoir of potential variability. Breaking up the genetic organisation of these complexes, however, usually affects more than one character. Apparently an example of this situation was encountered in the present experiment. A considerable increase in growth rate in some of the inter-strain crosses was obtained at the expense of fertility.

Selection for increased growth rate at three different temperatures corresponds to selection for improvement of three different characters. Although statistical differences could be demonstrated among these characters, there was obviously enough similarity between them to suggest that each was, to a large extent, controlled by the same set of genes. To test this hypothesis, genetic correlations, calculated in the manner described by Reeve and Robertson (1953), were computed. There was apparently no consistent pattern in the nature of responses to direct and indirect responses within and among the strains and replications. Therefore, rather gross estimates of genetic correlations were obtained by basing them on the average percentage gain over all strains and replications. The genetic correlations determined in this manner were $0.84,0.74$, and 0.73 between selections for improved growth rate at $\left(18^{\circ}\right.$ and $\left.25^{\circ}\right),\left(25^{\circ}\right.$ and $\left.35^{\circ}\right)$ and $\left(18^{\circ}\right.$ and $\left.35^{\circ}\right)$, respectively. Thus, in order to increase the growth rate at one temperature, selection at that temperature would be approximately 25 per cent. more effective than selection at either of the other two temperatures.

Comparisons among direct and indirect responses to selection at I $8^{\circ}, 25^{\circ}$ and $35^{\circ} \mathrm{C}$. at each cycle of selection would have been desirable. From such comparisons it might have been possible to follow any step-wise canalisation of genotypes which apparently was operating at each temperature. Crosses among improved lines arising by continual selection at different temperatures would also have permitted genetical differentiation between the lines.

It is suggested that a differential maintenance and availability of genetic variation with temperature existed. Although temperature can influence the supply of genetic variation by affecting recombination, this effect was not considered relevant in these studies since all crosses were made at one temperature $\left(25^{\circ} \mathrm{C}\right.$. $)$. The retention and elimination of temperature sensitivity during selection at $25^{\circ}$ and $I 8^{\circ}$, respectively, 
was further evidence of the maintenance of more variability at $25^{\circ}$ than at $18^{\circ}$. Temperature sensitive allele(s) were presumably favored during selection for fast growth rate at $25^{\circ}$ but were at a disadvantage during selection for fast growth rate at $18^{\circ}$.

\section{SUMMARY}

1. Selection for fast growth rate was practised at 3 different temperatures in inter- and intra-strain crosses of Neurospora.

2. The greatest response, measured as the realised heritability, was obtained in crosses between the Honduras strains and the laboratory strains of either $74 \mathrm{~A}$ or $77 \mathrm{a}$. Infertility problems were generally encountered only in these crosses.

3. The least amount of progress was made in crosses between $74 \mathrm{~A}$ and 77 a.

4. Evidence of cytoplasmic effects on growth rate was confined to the progeny of one cross.

5. Selection at $35^{\circ}$ and $18^{\circ}$ resulted in greater response than did selection at $25^{\circ} \mathrm{C}$. Artificial selection at $25^{\circ}$ was presumably impeded by the effects of previous natural selection.

6 . Thus, selection for fast growth rate at 3 different temperatures corresponds to selection for the improvement of 3 different characters. Direct and indirect responses to selection for these 3 characters, however, suggested genetic correlations between them.

7. Temperature sensitive mutant allele(s) present in $74 \mathrm{~A}$, although eliminated early during selection at $35^{\circ}$ and $18^{\circ} \mathrm{C}$., were favored during selection at $25^{\circ} \mathrm{C}$.

Acknowledgments. -We acknowledge receipt of financial support from the Office of Naval Research through Contract No. Nonr-409(39), Project No. (NR 042-212) and in part from grant GM 12953 National Institutes of Health, U.S. Public Health Service. One of us (K.E.P.) acknowledges receipt of a traineeship from the National Institute of General Medical Sciences, NIH, Grant TI GM 1035.

The authors express their sincere thanks to Professor A. A. Fleming for his critical reading of the manuscript and to Mr Ronnie Morrison for skilfully inking and lettering the figures.

\section{REFERENCES}

BEADLE, G. W., AND TATUM, E. L. 1945. Neurospora II. Methods of producing and detecting mutations concerned with nutritional requirements. Amer. F. Bot., $32,678-686$.

BODMER, W. F., AND PARSONS, P. A. 1962. Linkage and recombination in evolution. Adv. Genet., II, I-IOO.

CHAPMAN, A. B. 196I. Contributions of laboratory animals to research in livestock improvement. Germ Plasm Resources. American Association for the Advancement of Science. Washington, D.C.

CROFT, J. H., AND SIMCHEN, G. 1965. Natural variation among monokaryons of Collybia velutipes. Amer. Natur., 99, 45 I-462.

FALCONER, D. S. 1955. Patterns of response in selection experiments with mice. Cold Spr. Harb. Symp. Quant. Biol., 2o, 178-196.

FEDERER, W. T., PAPA, K. E., AND SRB, A. M. 1966. Selection models. Biometrics (manuscript in process of publication). 
KOJIMA, KEN-ICHI, AND KELLEHER, THERESE. I96I. Selection studies of quantitative traits with laboratory animals. Statistical Genetics and Plant Breeding Symposium. Nat. Acad. Sci.-Nat. Res. Council Pub. 982, pp. 396-422.

LEE, B. T. O. I962. Studies concerning the inheritance of ascospore length in Neurospora crassa. II. Selection experiments with wild type strains. Austr. $\mathcal{F}$. Biol. Sci., 15, 160-165.

LEE, B. T. O., AND PATEMAN, J. A. 1959. Linkage of polygenes controlling size of ascospore in Neurospora crassa. Nature, ${ }^{8} 83,698-699$.

LEE, B. T. O., AND PATEMAN, J. A. I $96 \mathrm{I}$. Studies concerning the inheritance of ascospore length in Neurospora crassa. I. Studies on large-spored strains. Austr. $\mathcal{F}$. Biol. Sci., 14, 223-230.

LERNER, I. M. I954. Genetic Homeostasis. Oliver and Boyd, London.

MATHER, K., AND harrison, B. J. I949. Manifold effects of selection. Heredity, 3, I-52, 131-162.

PAPA, K. E. 1964. Effectiveness of selection based on variability uncomplicated by heterotic effects in Neurospora. ONR Technical Report No. 18, Contract No. Nonr-409(39), Project No. (NR 042-21 2), Cornell University.

pateman, J. A. 1955. Polygenic inheritance in Neurospora. Nature, I76, 1 274 -1 275.

pateman, J. A. 1959. The effect of selection on ascospore size in Neurospora crassa. Heredity, 13, 1-21.

PAteman, J. A., AND LEe, B. T. o. 1960. Segregation of polygenes in ordered tetrads. Heredity, $15,35 \mathrm{I}-36 \mathrm{r}$.

REEVE, E. C. R., AND ROBERTSON, F. W. 1953. Studies in quantitative inheritance. II. Analysis of a strain of Drosophila melanogaster selected for long wings. $\mathcal{J}$. Genet., 5I, 276-316.

ROBson, D. S. 1957. Some biometrical formulæ for the analysis of quantitative inheritance systems involving two haploid or inbred diploid parents. Genetics, 42, 487-498.

ROBSON, D. S. rg6o. Genetic and statistical theory for quantitative inheritance studies of haploids. Biometrical Genetics. Pergamon Press. pp. 46-64.

RYAN, F. J., BEADLE, G. W., AND TATUM, E. L. I943. The tube method of measuring the growth rate of Neurospora. Amer. J. Bot., 3o, 784-799.

simCheN, G. 1965. Variation in a dikaryotic population of Collybia velutipes. Genetics, 51, 709-721.

SIMCHEN, G., AND JINKS, J. L. I964. The determination of dikaryotic growth rate in the Basidiomycete Schizophyllum commune: A biometrical analysis. Heredity, 19, 629-649.

THODAY, J. M. 1958. Homeostasis in a selection experiment. Heredity, I2, 40 I-416. THOMPSON, K. I960. Techniques and related genetic results for a quantitative inheritance study in Neurospora crassa. Biometrics Unit, Cornell University, Mimeograph Series. BU-I 45-M.

WESTERGAARD, M., AND MITCHELL, H. K. I947. Neurospora V. A synthetic medium favoring sexual reproduction. Amer. F. Bot., 34, 573-577. 